\title{
Specific dynamic action, postprandial thermophily, and the impact of temperature on gastric digestion in the cornsnake Pantherophis guttatus
}

\author{
Lynnette M Sievert", Yusuke Suita, Daphne M Mayes, Lynett R Bontrager, Michelle Tuttle and Ashley Everly
}

\begin{abstract}
Background: The purpose of this work was to study the role of feeding on the energetics of cornsnakes.

Results: We measured oxygen consumption in cornsnakes prior to a meal and 6, 15, 20, 30, 40, 48, 72, and $96 \mathrm{~h}$ after eating a meal that was equivalent to $10 \%$ of the snake's body mass. We monitored temperature selection of individual cornsnakes in a thermal gradient in the spring and again in the fall when snakes were starved, digesting a meal equivalent to $10 \%$ of its body mass, and digesting a meal equivalent to $25 \%$ of its body mass. We measured the gastric digestion rate by monitoring the passage of magnetic stir bars, placed inside a mouse meal, through the digestive tracts of cornsnakes maintained at $22^{\circ} \mathrm{C}, 25^{\circ} \mathrm{C}, 28^{\circ} \mathrm{C}$, and $32^{\circ} \mathrm{C}$.

Conclusions: Oxygen consumption peaked at 2.3 times higher than baseline levels $24 \mathrm{~h}$ after feeding and had returned to pre-feeding levels by $72 \mathrm{~h}$. Meal size affected temperature selection in both seasons; in fall, starved snakes selected lower body temperatures than fed snakes, but meal size had no effect on temperature selection by fed snakes. Passage rates from the stomach to the intestine did not significantly differ among the temperatures studied.
\end{abstract}

Keywords: Energetics; Snake; Thermophily; Digestion

\section{Background}

To understand the natural history and energy flow of a snake species, both ecological and physiological studies are required (Dorcas et al. 2004). Food, shelter, and water are essential requirements for snakes, as is the availability of adequate thermal microhabitats for altering body temperature. Snakes alter their body temperatures because the rates of most physiological processes are dependent on temperature (Blouin-Demers and Weatherhead 2001a). The purpose of this research was to determine the effects of temperature selection due to feeding on several physiological rates of the cornsnake Pantherophis guttatus.

Feeding provides energy, but it results in metabolic rates that exceed those when fasting (Secor 2009), and this frequently leads to an elevated body temperature in snakes, both of which increase energy consumption. Although most snake species eat small, frequent meals,

\footnotetext{
* Correspondence: Isievert@emporia.edu

Department of Biological Sciences, Emporia State University, Emporia, KS 66801, USA
}

\section{Springer}

there are relatively few thorough studies on the feeding physiology of these snakes.

A snake's body temperature is dependent on external heat sources and can be behaviorally controlled by selecting appropriate microhabitats (Bontrager et al. 2006). Temperature plays a major role in rates of food consumption and digestion in reptiles, such as the cornsnake, P. guttatus (Greenwald and Kanter 1979; Blouin-Demers and Weatherhead 2001a). Cornsnakes are native to the southeastern USA (Love and Love 2005) where they are able to control their body temperature by moving among different microhabitats, allowing them to decrease their body temperature and metabolic rate when food is unavailable or increase body temperature to facilitate rapid digestion and energy assimilation for growth, reproduction, and body maintenance (Bontrager et al. 2006). Cornsnakes consume small mammals and birds (Love and Love 2005). This food provides nutrients and calories, but processing a meal has costs, which can readily be measured as elevated oxygen consumption for an interval of time after feeding (Secor 2009). Feeding provides snakes with energy, 
but the elevated metabolic rate and thermophily increase energy consumption.

The specific dynamic action (SDA), i.e., the cost of processing a meal, includes all of the energy expended to ingest, digest, absorb, and use nutrients in anabolic reactions, such as protein synthesis (Secor 2009). The choice of prey has an impact on the SDA; hard-bodied meals produce greater increases in oxygen consumption than soft-bodied meals (Hailey 1998; Secor and Boehm 2006; Secor et al. 2007; Bessler et al. 2010), and larger meals yield higher SDA values than smaller meals of a given prey type (Andrade et al. 1997; Secor and Diamond 1997; Toledo et al. 2003). Typically, higher temperatures shorten the SDA and reduce the intervals between feeding and peak oxygen consumption (Toledo et al. 2003; Bessler et al. 2010). Snakes eat different types and sizes of prey and may or may not be able to elevate their body temperature, so SDA profiles can vary greatly, even in a single individual. Cornsnakes actively forage and frequently feed and are therefore expected to have lower SDA values than sit-and-wait, infrequent feeders, such as pythons and rattlesnakes (Secor 2009). Cornsnakes maintain energetically active organs between meals, and this leads to a higher resting metabolic rate than for large, infrequently feeding snakes such as pythons and rattlesnakes. Therefore, the increase in oxygen consumption after feeding is greater in infrequently feeding snakes that not only digest but rebuild atrophied tissues (Secor 2009).

A second aspect in determining energy consumption is body temperature. Snakes can easily change their body temperature by selecting appropriate ambient temperatures or by basking. Elevated body temperatures can shorten digestive times (Toledo et al. 2003), allowing a snake to engage in non-feeding or subsequent feeding activities sooner. Therefore, it is not surprising that after a meal, snakes often behaviorally raise their body temperatures (Greenwald and Kanter 1979; Touzeau and Sievert 1993; Sievert and Andreadis 1999). In many studies of temperature on the SDA, an animal is placed at temperatures chosen by the authors without regard to temperatures selected by the animal. For species with postprandial thermophily, this is not an accurate simulation of pre- and post-feeding physiology. One of our goals was to measure the energetic cost of digestion at temperatures selected by starved snakes and postprandial snakes. Calculation of the total cost of digestion must include both the SDA and thermophily.

Snakes feed on a wide range of prey sizes, and some species can consume a meal that exceeds their own body mass (Secor and Diamond 1997). Therefore, it seems reasonable that meal size can affect the degree of postprandial thermophily. Bontrager et al. (2006) hypothesized that larger meals would induce greater thermophily than smaller meals. They fed cornsnakes meals of $5 \%$ or $10 \%$ of the snakes' body mass; however, the meal size did not change the amount of thermophily. Given the large range of meal sizes a cornsnake can consume, the range of meal sizes in that study might not have been great enough to elicit a difference. We tested whether a meal of $>10 \%$ of a snake's body mass would increase thermophily.

In addition to the effects of SDA and thermophily on energy use, snakes face changing thermal environments in seasons during which they are active. Several studies showed that squamate reptiles select higher body temperatures in spring or spring and autumn than in summer (Patterson and Davies 1978; Scott and Pettus 1979; Sievert and Hutchison 1989) in a laboratory thermal gradient. Scott and Pettus (1979) suggested that snakes acclimated to cool spring temperatures would seek warm body temperatures to aid digestion and reproduction. Australian black snakes, Pseudechis porphyriacus, selected warmer temperature in spring than summer in the field, but this was attributed to lower activity levels caused by limited prey availability due to a summer drought (Shine and Lambeck 1990). Two lizards, Crotaphytus collaris and Lacerta vivipara, selected warmer body temperatures in spring and fall than in summer (Patterson and Davies 1978; Sievert and Hutchison 1989), but C. collaris only exhibited this when tested in a thermal gradient with a point source of light over the hot end of the gradient and not when there was uniform light overhead. Nerodia rhombifera selected higher body temperatures during summer than winter regardless of the acclimation temperature or photoperiod in a laboratory thermal gradient ( $\mathrm{Tu}$ and Hutchison 1995). Other squamate reptiles showed no seasonal variation in selected body temperature in the field (Moore 1978; Rosen 1991) or laboratory (Case 1976). These examples demonstrate that season can influence temperature selection, but it is unclear if seasonal differences in temperature selection are typical of snakes. In the only study to look at a seasonal effect on postprandial thermophily in cornsnakes, P. guttatus elevated its body temperature after feeding in fall (September to November), but not in winter (January to February) in a thermal gradient (Greenwald and Kanter 1979). Cornsnakes normally hibernate in winter, and therefore, it seems plausible that season could impact postprandial thermophily at the onset or end of their active season.

The transit time, the time from ingestion to defecation, is used as a measure of the digestive rate. This is problematic because transit time is under both physiological and behavioral control in snakes. Many snakes retain feces for a long time after digestion (Lillywhite et al. 2002), and in those species, transit time provides no information on physiological processes. For example, cornsnakes rarely defecate while in ecdysis (Sievert et al. 2005) and retain feces until after shedding. In contrast, gastric digestion, the time the meal is in the stomach, is not under behavioral control and therefore is a better indicator of the effect of 
temperature on digestion than the transit time. In addition, gastric digestion rates are relevant in determining minimal intervals between successive meals, while transit times are not.

We chose to work with cornsnakes because this species is easily maintained in captivity, captive-born individuals are readily available in the pet trade (Love and Love 2005), and there is some literature regarding their digestive physiology (Greenwald and Kanter 1979; Sievert et al. 2005; Bontrager et al. 2006). They readily feed and have a geographic range with an annual cycle in temperature. Cornsnakes are generalist feeders and feed at frequent intervals compared to megasnakes like boas, pythons, and large vipers; therefore, studying them could give information that is applicable to the majority of snake species and not just extreme feeders. Because megasnakes can eat large, infrequent meals that result in increases in oxygen consumption greater than those seen with maximal exercise (Andrade et al. 1997; Secor and Diamond 1997), much investigation has gone into elucidating mechanisms on how such snakes juggle digestive physiology and respiratory control or $\mathrm{pH}$ balance (Overgaard et al. 1999; Wang et al. 2001).

Our purpose was to increase understanding of the role of feeding on the energetics of cornsnakes. Feeding involves a complex interaction of behavior, ecology, and physiology, some aspects of which can be modified through thermoregulation. By selecting for prey size and body temperature, cornsnakes could potentially shorten the interval between meals and consume a greater amount during their active season. This would be beneficial to both young snakes to help them grow more quickly and adults who need energy for continued growth, cell maintenance, and reproduction. Cornsnakes can exert control over their body temperature by selecting appropriate microhabitats, but this may be harder in the spring and fall when environmental temperatures are lower. Cornsnakes feed mainly on rodent and bird prey; therefore, meal size changes with the type and number of prey items eaten. If feeding induces thermophily, it may reduce gastric digestion times and allow snakes to feed more frequently, but the energetic costs of the SDA and thermophily will be higher than at pre-feeding body temperatures. We wanted to determine if either meal size or season affected postprandial thermophily of cornsnakes and if higher body temperatures increased the rate of gastric digestion. Postprandial thermophily was observed in cornsnakes (Bontrager et al. 2006), yet its impact on energetics and whether or not it speeds gastric digestion, therefore allowing feeding at shorter intervals, are not known. There is some indication that the time of year determines if postprandial thermophily occurs (Greenwald and Kanter 1979), but these data were gathered at a time of year when cornsnakes are normally inactive. It is unknown if cornsnake thermoregulation is influenced by the time of year. Cornsnakes are capable of eating a wide range of meal sizes, but it has not been demonstrated whether meal size has any impact on their degree of postprandial thermophily. Feeding leads to an increase in selected body temperature by cornsnakes in the laboratory, and both feeding and higher body temperatures elevate metabolism; however, we do not know if either season or meal size influences this relationship.

A number of studies looked at the SDA or postprandial thermophily in various snake species, but few examined if season alters thermoregulation. This makes it hard to predict how these factors might impact energetics in a given species. Therefore, our purpose was to study the individual effects of eating an average-sized meal on the metabolic rate and temperature selection and to test whether meal size or time of year influences thermophily. We also determined if thermophily could increase the rate of gastric digestion, since this is important in determining when a snake will be willing to take its next meal. We tested four hypotheses: (1) the SDA of cornsnakes is relatively small, (2) cornsnakes display postprandial thermophily with larger meals inducing greater thermophily, (3) the time of year affects postprandial thermophily, and (4) increasing the body temperature speeds the rate of gastric digestion.

\section{Methods}

\section{Snake housing}

Snakes in these experiments were part of a cornsnake colony maintained at Emporia State University (Emporia, KS, USA). All snakes were captive born and were housed in size-appropriate containers. Each snake was housed alone in a newspaper-lined acrylic chamber with ventilation and had constant access to water and a retreat for hiding. Snakes were maintained this way between experiments and were habituated to frequent handling. Between experiments, snakes were maintained on a 12:12-h light (L)/ dark (D) photoperiod at room temperature in the laboratory. Snakes were fed size-appropriate meals at intervals of 2 weeks or less, depending upon the snake's age.

\section{SDA}

Eight 3-year-old cornsnakes (with a mass of $114.65 \pm 3.22 \mathrm{~g}$; range, 102.9 to $127.6 \mathrm{~g}$ ) were placed in a constant temperature chamber at $25^{\circ} \mathrm{C}$ on a $12: 12-\mathrm{h} \mathrm{L} / \mathrm{D}$ photoperiod with the photophase at 6:00 to 18:00 Central Daylight Time (CDT). Snakes were starved for 6 days before we began the experiment. During the experiment, none of the snakes was in ecdysis, and all reliably fed when offered a meal.

Each snake was weighed at the beginning of the experiment, and we used this mass to calculate the meal size. Thirty minutes before measuring oxygen consumption, we habituated a snake to a $790-\mathrm{mL}$ opaque test chamber 
with a ventilated lid. Just prior to data collection, we replaced the ventilated lid with a tightly fitting lid that housed both air inflow and outflow tubes. Air passed from the test chamber through a tube of Drierite and a tube of soda lime and on to a Qubit Systems Flow Through Oxygen Sensor (S102, Qubit Systems Inc., Kingston, Ontario, Canada). The oxygen sensor was calibrated with nitrogen gas and then room air. Room air at $25^{\circ} \mathrm{C}$ (range, $24.3^{\circ} \mathrm{C}$ to $26.3^{\circ} \mathrm{C}$ ) passed through the system at $160 \mathrm{ml} / \mathrm{min}$. Oxygen consumption was monitored for $15 \mathrm{~min}$ unless the oxygen concentration in the outflow air was variable (due to snake activity). In that case, monitoring continued until the oxygen concentration in the outflow air became constant. Data were gathered by Logger Pro 3.2 software (Vernier Software and Technology, Beaverton, OR, USA). Oxygen consumption was measured before feeding and at $6,15,20,24,30,40,48,72$, and $96 \mathrm{~h}$ after a snake had eaten a mouse meal equivalent to $10 \%$ of its body mass (mean, 10.08\% $\pm 0.41 \%$; range, $9.4 \%-10.9 \%$ ). All measurements were made at 8:00 to 19:00 CDT to avoid any influence of a diel cycle in oxygen consumption. To obtain measurements that occurred outside this time, a snake was fed a second time after obtaining measurements that occurred at 8:00 to 19:00 CDT. Instead of feeding the snakes in the morning, the second feeding occurred in the evening, and data for the missing times were gathered beginning the next day. After each test session, the snake was removed from the chamber and placed in its home container.

Data were converted to standard temperature and pressure and analyzed using Bartlett's test of variance of homogeneity. This was followed by a repeated measures one-way analysis of variance (ANOVA) and then with a Student-Neuman-Keuls (SNK) multiple comparison procedure. Values were considered significant at $p \leq 0.05$. We calculated the area above baseline oxygen consumption levels from time 0 to $72 \mathrm{~h}$ to measure the cost of SDA.

\section{Thermoregulation}

We maintained the cornsnakes at $25^{\circ} \mathrm{C}$ and a $12: 12-\mathrm{h} \mathrm{L} / \mathrm{D}$ photoperiod as previously described. All snakes were starved for 5 days and then placed into one of the three groups: starved, fed a meal equivalent to $10 \%$ of its body mass, or fed a meal equivalent to $25 \%$ of its body mass. Each snake participated in all three treatment groups at some point during the experiment, and body mass was determined all three times the snake entered the thermal gradient. Each snake was individually habituated to a 20 -cm-wide $\times 90$-cm-long linear thermal gradient with an aluminum floor for $24 \mathrm{~h}$. Floor temperatures ranged $15^{\circ} \mathrm{C} \pm 1^{\circ} \mathrm{C}$ to $40^{\circ} \mathrm{C} \pm 1^{\circ} \mathrm{C}$. A subsurface heater maintained the hot end of the gradient at $40^{\circ} \mathrm{C}$, and a second subsurface heater in the middle of the gradient set at $25^{\circ} \mathrm{C}$ maintained the linear gradient. Snakes had access to water at all times and could hide under a 10-cm-wide foam board that extended down the length of the gradient at a $45^{\circ}$ angle from one edge. Snakes that were not given the opportunity to hide did not display postprandial thermophily (Tsai and $\mathrm{Tu} 2005$ ). The foam board allowed the snake to hide at any temperature between $15^{\circ} \mathrm{C}$ and $40^{\circ} \mathrm{C}$. The substrate temperature under each snake was recorded at 8:00, 11:00, 14:00, 17:00, and 20:00 CDT by placing a type $\mathrm{K}$ thermocouple, attached to a Kane May data logger (Comark Limited, Welwyn Garden City, Herts, Great Britain) under the stomach of the snake. Snake meals were given after we recorded the temperature at 8:00 CDT.

We used Bartlett's test of variance homogeneity followed by a two-way ANOVA to determine if there was an effect of treatment or time of day on temperature selection. As all snakes were fasting at 8:00 CDT, 8:00 CDT was not included in the analysis. We then used the SNK multiple comparison procedure test to determine which treatments significantly differed from each other. We conducted this experiment with 11 1.5-year-old snakes in April and May (i.e., in spring; with a body mass of $31.8 \pm 1.7 \mathrm{~g}$ ) and with 12 2-year-old snakes in October and November (i.e., in fall; with a body mass of $62.3 \pm 1.9 \mathrm{~g}$ ). Values were considered significant at $p \leq 0.05$.

\section{Gastric digestion rate}

Eight 5-year-old cornsnakes ranging in mass from 195 to $473 \mathrm{~g}$ were housed as described above in a constant temperature chamber with a 12:12-h L/D photoperiod. Snakes were randomly assigned to acclimate to a test temperature of $22^{\circ} \mathrm{C}, 25^{\circ} \mathrm{C}, 28^{\circ} \mathrm{C}$, or $32^{\circ} \mathrm{C}$, for at least 1 week before being tested at that temperature. By the end of the experiment, all individuals had been acclimated and tested at all four temperatures.

On the day of feeding, we weighed each snake and returned it to its home container. A magnetic stir bar $(12 \times 2 \mathrm{~mm})$ was inserted into the esophagus and another into the anus of a dead mouse (Temple 2002) with a mass equivalent to $10 \%$ of the snake's body mass. We fed each snake its corresponding mouse and placed it back into the acclimation chamber. At least $20 \mathrm{~min}$ was allowed for the meal to pass through the esophagus and into the stomach. Once a snake had ingested its meal, we took each snake from the acclimation chamber to collect our first data point.

The snake's head was guided into a clear acrylic tube with a diameter slightly larger than the snake's body, and the snake crawled into the tube. Initially, snakes resisted doing this, so we habituated them by repeatedly placing them in the tubes over the course of the week prior to any data collection. After habituation, the snakes willingly entered the tubes. We placed a foam stopper at the far end of the tube to ensure that the snake did not escape 


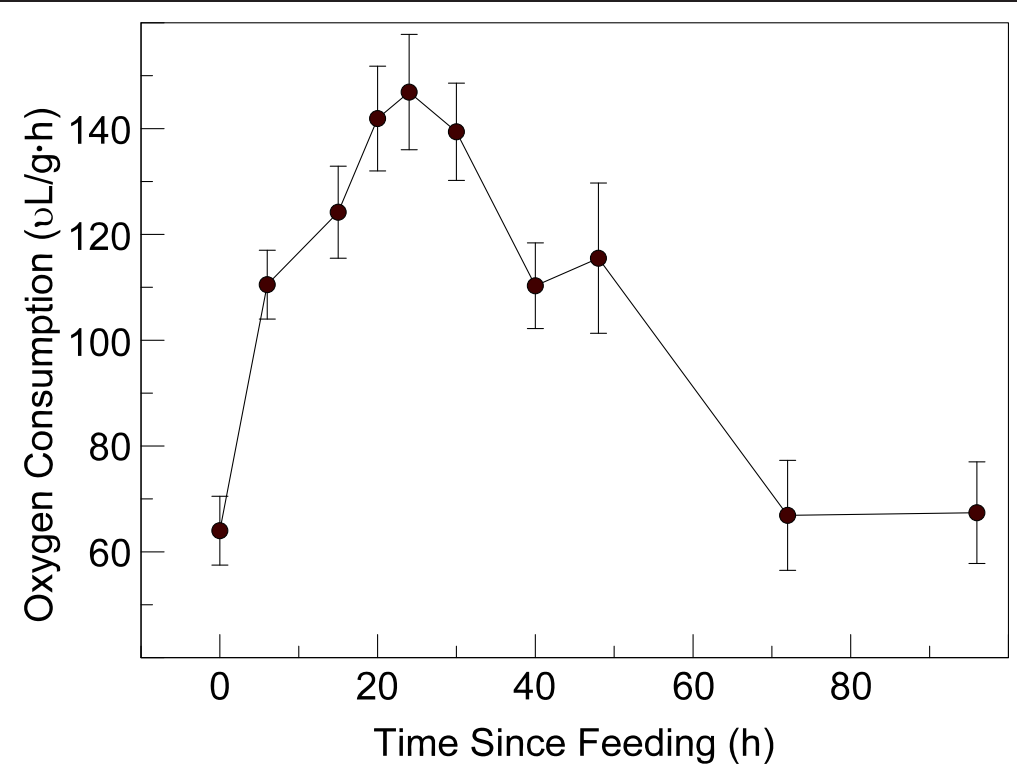

Figure 1 Oxygen consumption of eight juvenile cornsnakes at $26^{\circ} \mathrm{C}$. Snakes were fed just after the time 0 measurement. Circles are the means, and vertical bars are 1 standard error above and below the mean.

during measurement. Once the snake was in the tube, we passed a compass next to its body beginning at the head and ending at the tail. Once each stir bar was located, we measured the distance from the snout to its location and recorded it. We repeated this with all snakes every $24 \mathrm{~h}$ until both magnetic stir bars exited the stomach and entered the small intestine. The gastric digestive rate was measured as the first day each stir bar was no longer in the stomach. Within minutes of feeding, we were able to locate the stir bars within the stomach. Their positions changed very little for several days and then there was a noticeable change in position. In all cases, the two stir bars exited the stomach at different times.

We used Bartlett's test of variance homogeneity followed by a one-way ANOVA to measure the effect of temperature on the number of days it took the first stir bar to exit the stomach and another ANOVA for the second stir bar. A $t$ test was used to compare the amount of time it took the two stir bars to leave the stomach at each temperature. Values were considered significant at $p \leq 0.05$.

\section{Results}

\section{SDA}

Oxygen consumption significantly varied over the 96-h experimental period $(F=14.7, d f=9, p<0.001)$. Peak oxygen consumption occurred at $24 \mathrm{~h}$ post-feeding and was 2.3 times higher than fasting levels (Figure 1). Oxygen consumption had returned to its original value by $72 \mathrm{~h}$ post-feeding with the highest values observed at 6 to $48 \mathrm{~h}$ post-feeding (Table 1). At 0 to $72 \mathrm{~h}$, snakes consumed an additional $3.4 \mathrm{~mL}$ of oxygen per gram mass above the baseline level. For a 115-g snake, this was an additional
$393 \mathrm{~mL}$ of oxygen consumed over the baseline fasting value of $530 \mathrm{~mL}$ over a 72 -h period.

\section{Thermoregulation}

In spring, there was a significant difference in temperature selection among the feeding treatment groups $(F=4.571$, $d f=2, p=0.012$ ), but the SNK test could not separate the groups. The time of day had no effect on temperature selection $(F=1.656, d f=3, p=0.18)$, nor was there a significant interaction between treatment and time $(F=0.249$, $d f=6, p=0.959)$. The mean temperature selected by starved snakes was $25.8^{\circ} \mathrm{C} \pm 0.35^{\circ} \mathrm{C}$, by snakes fed a $10 \%$

\section{Table 1 Results of SNK multiple comparison tests} comparing oxygen consumption among the times since the snakes had eaten

\begin{tabular}{ccccccccccc}
\hline Time & $\mathbf{0}$ & $\mathbf{6}$ & $\mathbf{1 5}$ & $\mathbf{2 0}$ & $\mathbf{2 4}$ & $\mathbf{3 0}$ & $\mathbf{4 0}$ & $\mathbf{4 8}$ & $\mathbf{7 2}$ & $\mathbf{9 6}$ \\
\hline 0 & - & & & & & & & & & \\
6 & $* *$ & - & & & & & & & & \\
15 & $* * *$ & n.s. & - & & & & & & & \\
20 & $* * *$ & n.s. & n.s. & - & & & & & & \\
24 & $* * *$ & n.s. & n.s. & n.s. & - & & & & & \\
30 & $* * *$ & n.s. & n.s. & n.s. & n.s. & - & & & & \\
40 & $* *$ & n.s. & n.s. & n.s. & n.s. & n.s. & - & & & \\
48 & $* *$ & n.s. & n.s. & n.s. & n.s. & n.s. & n.s. & - & & \\
72 & n.s. & $*$ & $* * *$ & $* * *$ & $* * *$ & $* * *$ & $* *$ & $* *$ & - & \\
96 & n.s. & $* *$ & $* * *$ & $* * *$ & $* * *$ & $* * *$ & $* *$ & $* *$ & n.s. & - \\
\hline
\end{tabular}

Time 0 is just before the meal, and all other numbers represent the time in hours since the snake ate. n.s., not significant $(p>0.05) .{ }^{*} p \leq 0.05 ;{ }^{* *} p \leq 0.01$; ${ }^{* * *} p \leq 0.001$. 
meal was $28.3^{\circ} \mathrm{C} \pm 0.43^{\circ} \mathrm{C}$, and by snakes fed a $25 \%$ meal was $27.9^{\circ} \mathrm{C} \pm 0.74^{\circ} \mathrm{C}$ (Figure 2a).

In fall, there was a difference in temperature selection among the treatment groups $(F=9.338, d f=2, p=0.0006)$. Temperatures selected by starved snakes were lower than those selected by snakes fed $10 \%(p=0.0005)$ and $25 \%(p=0.0166)$ meals, but there was no difference in substrate temperatures selected by the two groups of fed snakes $(p>0.05)$. The time of day had no effect on temperature selection $(F=0.32, d f=3, p=0.81)$ nor was there a significant interaction between the treatment and time $(F=1.674, d f=6, p=0.13)$. The mean temperature selected by starved snakes was $26.1^{\circ} \mathrm{C} \pm 0.45^{\circ} \mathrm{C}$, by snakes fed a $10 \%$ meal was $29.2^{\circ} \mathrm{C} \pm 0.56^{\circ} \mathrm{C}$, and by snakes fed a $25 \%$ meal was $27.9^{\circ} \mathrm{C} \pm 0.24^{\circ} \mathrm{C}$ (Figure $2 \mathrm{~b}$ ).

\section{Gastric digestion rate}

Temperature had no effect on the time it took for the first stir bar to pass from the stomach into the small intestine $(F=1.305, d f=3, p=0.29)$. Temperature almost had a significant effect on the passage time of the second stir bar into the small intestine $(F=2.81, d f=3, p<0.06)$. There was a significant lag time $(p<0.05)$ between the passage of the first and second stir bars at all four test temperatures (Figure 3).

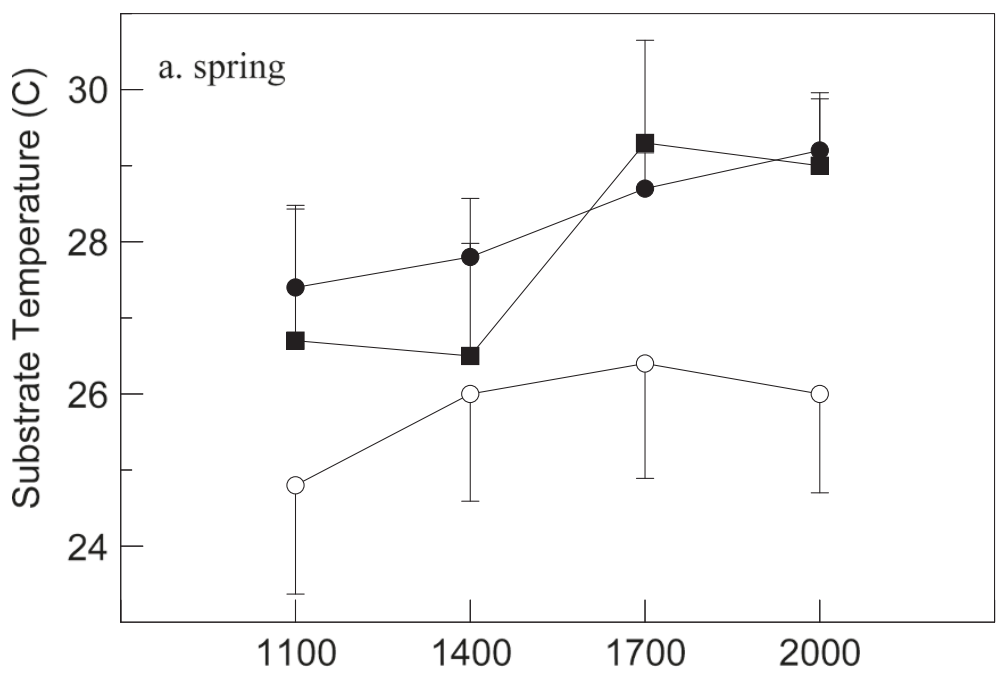

Time (h)

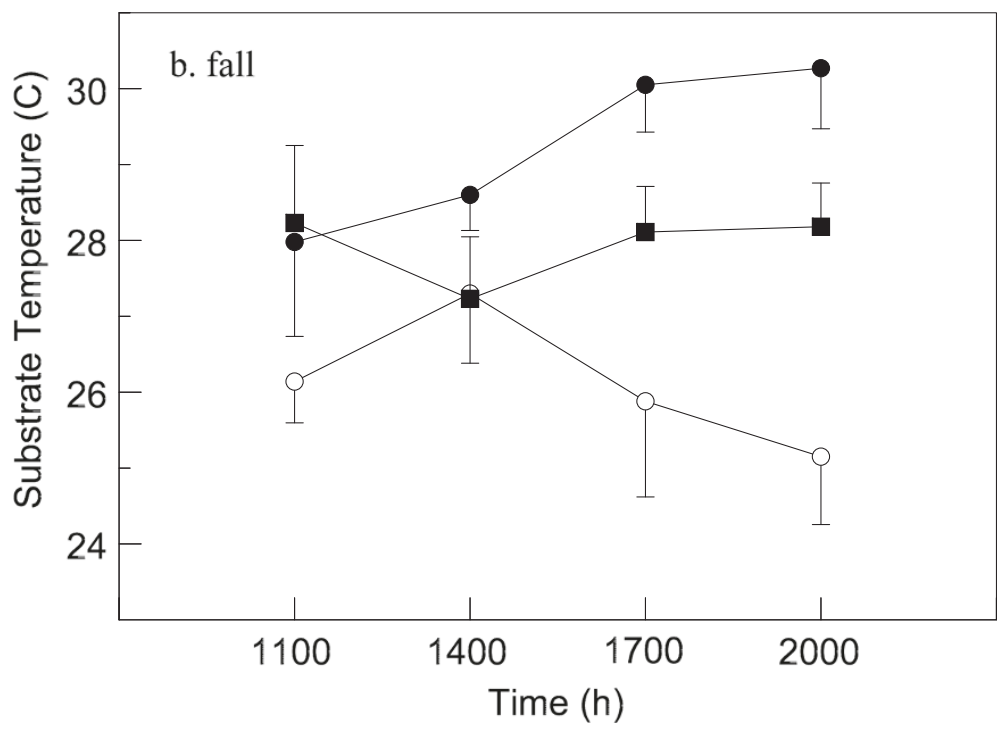

Figure 2 Substrate temperatures under the stomachs of juvenile cornsnakes after feeding. Snakes were given a meal equivalent to $10 \%$ or $25 \%$ of their body mass or were not fed. The mean and 1 standard error above and below the mean are shown. Closed circles (•) are starved snakes, open circles (o) are snakes fed a meal equivalent to $10 \%$ of their body mass, and filled squares (.) are snakes fed a meal equivalent to $25 \%$ of their body mass. (a) In spring, $n=11$ per group. (b) In fall, $n=12$ per group. 


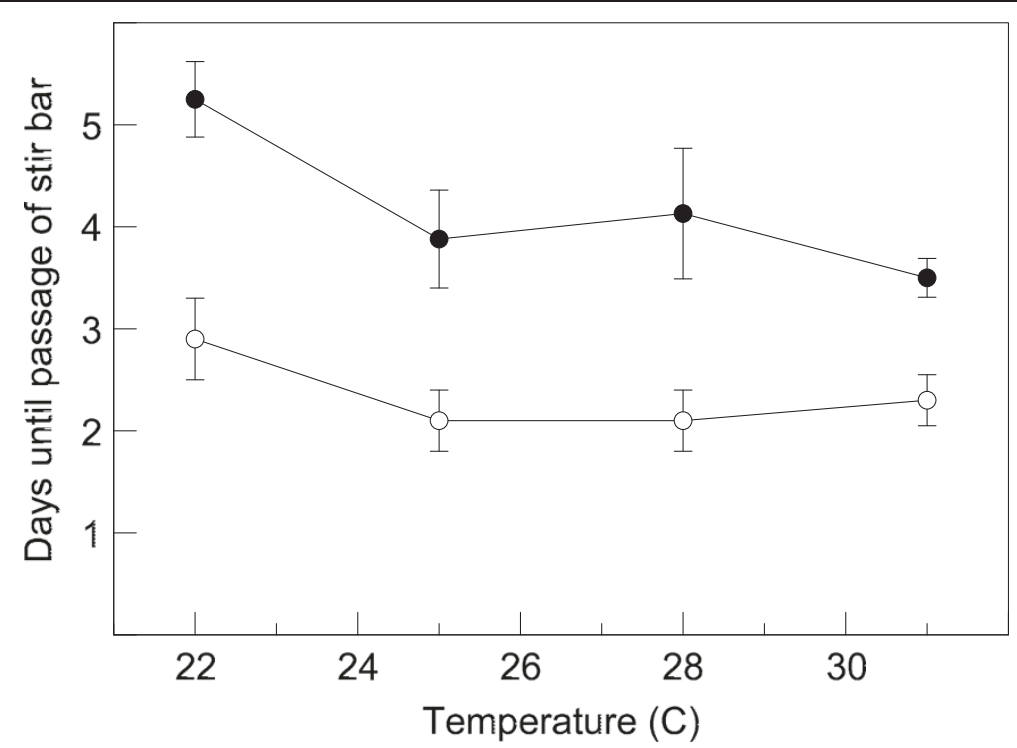

Figure 3 Gastric digestion time in cornsnakes. Time after eating a meal equivalent to 10\% of a snake's body mass until a magnetic stir bar passed from the stomach to the small intestine. Stir bars were placed in both the anus and esophagus of the prey. Open circles (o) represent the mean time for the first stir bar to pass into the small intestine, and closed circles $(\bullet)$ represent the mean time for the second stir bar to pass into the small intestine. Vertical bars represent 1 standard error above and below the mean. $n=8$ snakes at each temperature.

\section{Discussion}

\section{SDA}

Our results supported our first hypothesis. The peak SDA value was 2.3 times higher than baseline levels and occurred at $24 \mathrm{~h}$ after snakes ate the $10 \%$ body mass meal. There are numerous literature reports on snakes with much greater peak SDA values (for a review, see Secor 2009), but our results agree with the observation that frequently feeding snakes have smaller SDA responses than snakes that eat large, infrequent meals (Secor and Phillips 1997; Secor 2001). The peak occurred at $24 \mathrm{~h}$, and the SDA was completed within $72 \mathrm{~h}$ of feeding. This time frame agrees with other studies on snakes fed moderately sized meals (Secor and Diamond 1997; Bessler et al. 2010). Modest-sized meals consumed by cornsnakes in our study led to SDA values that were low enough to allow the snakes to engage in bouts of exercise, such as escaping predators, while digesting.

\section{Thermoregulation}

We rejected our second hypothesis that meal size would directly affect the amount of postprandial thermophily. Starved snakes in both the spring and fall selected lower body temperatures than individuals fed either the $10 \%$ or $25 \%$ body mass meals. Starved hatchling cornsnakes selected cooler temperatures than snakes fed small meals of $10 \%$ of their body mass at $3 \mathrm{~h}$ after eating, but there were no differences in temperature selection between snakes fed the $5 \%$ or $10 \%$ body mass meal (Bontrager et al. 2006). The size of the meal also did not influence temperature selection in our study. Although many snakes can eat meals much greater than $25 \%$ of their body mass (Andrade et al. 1997; Bessler et al. 2010), we noted that adult cornsnakes will frequently not take meals of $25 \%$ of their body mass. In our lab, adult cornsnakes would consistently not eat meals of $>16 \%$ of their body mass (T Prendergast and L Sievert, unpublished data). Therefore, we feel that increasing the meal size to $>25 \%$ body mass would not have produced reliable results for adult cornsnakes.

Seeking warmer body temperatures after feeding speeds digestion, allowing a juvenile snake to eat more and grow more during its activity season (Sievert and Andreadis 1999). Seeking heat during the day is not the only way to increase the mean body temperature. Gravid black ratsnakes (Pantherophis obsoletus) in the field increase their mean body temperatures not by seeking higher warm temperatures but by avoiding lower temperatures at night (Blouin-Demers and Weatherhead 2001b). This behavior yields higher mean body temperatures. Black ratsnakes are more likely to be found basking in the field and selected higher mean temperatures in a laboratory thermal gradient after a meal (Blouin-Demers and Weatherhead 2001a). We did not look at nighttime body temperatures to see if P. guttatus increased its body temperature at night after feeding. Digestive enzymes function best at optimal temperatures (Withers 1992), and above or below these temperatures, enzyme functions decrease.

Postprandial thermophily was similar in spring and fall, supporting our third hypothesis. Both seasons potentially have cool temperatures that inhibit digestion. Therefore, postprandial thermophily may be most important during 
these seasons. During the summer, appropriate temperatures for digestion are easier to obtain, but overheating can be a problem. This is in keeping with observations that reptiles may seek cooler temperatures in the summer than in the spring or fall (Scott and Pettus 1979; Sievert and Hutchison 1989). Cornsnakes increased their body temperature by several degrees after a meal, but neither season nor meal size altered the amount of postprandial thermophily.

\section{Gastric digestion rate}

Our data do not support our fourth hypothesis that temperature affects gastric digestion over the ranges of temperatures we tested. We chose test temperatures which our snakes could tolerate indefinitely and still reliably digest their food. Wild snakes would likely encounter a greater range of temperatures but would not spend several weeks at these temperatures as our test subjects did. A meal of $10 \%$ of the body mass did not exit the stomach in 1 pulse. The magnetic markers we placed at either end of the mouse passed into the intestine at significantly different times at all test temperatures. Over this range, temperature had no effect on when the first stir bar left the stomach. The stir bar at the posterior end of the mouse took over a day longer to leave the stomach at $22^{\circ} \mathrm{C}$ than at $32^{\circ} \mathrm{C}$. Our technique was chosen to minimize handling effects on the results, but only allowed us to monitor the marker's location at 24-h intervals. Despite this, we feel that temperatures within this range probably had minimal impacts on the gastric digestion rate. This minimal effect on gastric digestion over the $10^{\circ} \mathrm{C}$ interval commonly encountered by cornsnakes means they can engage in activities other than thermoregulation without impacting digestion.

\section{Conclusion}

In summary, cornsnakes fed meals of $10 \%$ or $25 \%$ of their body mass selected higher substrate temperatures than did starved snakes. This pattern was similar in both the spring and fall. Cornsnakes display an SDA pattern that peaked at $24 \mathrm{~h}$ and was complete at $72 \mathrm{~h}$ when fed a meal at $10 \%$ of their body mass and maintained at $25^{\circ} \mathrm{C}$. The peak SDA was more than double baseline values. This level of increase in oxygen consumption still allows cornsnakes to be active if required while digesting. Finally, we did not see a significant effect of temperature on the gastric digestion rate. Over the temperature range we tested, increasing the temperature from $22^{\circ} \mathrm{C}$ to $32^{\circ} \mathrm{C}$ did not cause food to move from the stomach to the intestine more quickly. Not having to maintain body temperature within a small range allows cornsnakes to engage in activities other than thermoregulation and utilize a greater proportion of their habitat after feeding without greatly altering the gastric digestion rate.
Competing interests

The authors declare that they have no competing interests.

\section{Authors' contributions}

LMS carried out the snake care, data collection, and data analysis and drafted the manuscript, YS, DMM, LRB, MT, and AE carried out the snake care and data collection. All authors read and approved the final manuscript.

\section{Acknowledgements}

This project was supported by NIH grant P20 RR016475 from the INBRE Program of the National Center for Research Resources (Bethesda, MD, USA). The content is solely the responsibility of the authors and does not necessarily represent the official views of the National Center for Research Resources or the National Institutes of Health. We thank the Biology Department of Emporia State University (Emporia, KS, USA) for the laboratory space, equipment, and support. This protocol was approved by the Emporia State University Animal Care and Use Committee (ESU-ACUC-02-014, ESUACUC-06-001, and ESU-ACUC-09-10).

Received: 10 January 2012 Accepted: 22 March 2013 Published: 7 October 2013

\section{References}

Andrade DV, Cruz-Neto AP, Abe AS (1997) Meal size and specific dynamic action in the rattlesnake Crotalus durissus (Serpentes: Viperidae). Herpetologica 53:485-493

Bessler SM, Stubblefield MC, Ultsch GR, Secor SM (2010) Determinants and modeling of specific dynamic action for the common garter snake (Thamnophis sirtalis). Can J Zool 88:808-820

Blouin-Demers G, Weatherhead PJ (2001a) An experimental test of the link between foraging, habitat selection and thermoregulation in black rat snakes Elaphe obsoleta obsoleta. J Anim Ecol 70:1006-1013

Blouin-Demers G, Weatherhead PJ (2001b) Thermal ecology of black rat snakes (Elaphe obsoleta) in a thermally challenging environment. Ecology 82:3025-3043

Bontrager LR, Jones DM, Sievert LM (2006) Influence of meal size on postprandial thermophily in cornsnakes (Pantherophis guttatus). Transact KS Acad Sci 109:184-190

Case TJ (1976) Seasonal aspects of thermoregulatory behavior in the chuckawalla, Sauromalus obesus (Reptilia, Lacertilia, Iguanidae). J Herpetol 10:85-95

Dorcas ME, Hopkins WA, Roe JH (2004) Effects of body mass and temperature on standard metabolic rate in the eastern diamondback rattlesnake (Crotalus adamanteus). Copeia 2004:145-151

Greenwald OE, Kanter ME (1979) The effects of temperature and behavioral thermoregulation on digestive efficiency and rate in corn snakes (Pantherophis guttatus guttata). Physiol Zool 52:398-408

Hailey A (1998) The specific dynamic action of the omnivorous tortoise Kinixys spekii in relation to diet, feeding pattern, and gut passage. Physiol Zool 71:57-66

Lillywhite HB, de Delva P, Noonan BP (2002) Patterns of gut passage time and the chronic retention of fecal mass in viperid snakes. In: Schuett GW, Hoggren M, Douglas ME, Greene WH (eds) Biology of the vipers. Eagle Mountain Publishing, Eagle Mountain, pp 497-506

Love K, Love B (2005) Corn snakes: the comprehensive owner's guide. The Herpetocultural Library. Advanced Vivarium Systems, Irvine

Moore RG (1978) Seasonal and daily activity patterns and thermoregulation in the southwestern speckled rattlesnake (Crotalus mitchelli Pyrrhus) and the Colorado desert sidewinder (Crotalus cerastes laterorepens). Copeia 1978:439-442

Overgaard J, Busk M, Hicks J, Jensen FB, Wang T (1999) Respiratory consequences of feeding in the snake Python molorus. Compar Biochem Physiol A 124:359-365

Patterson JW, Davies PMC (1978) Preferred body temperature: seasonal and sexual differences in the lizard Lacerta vivipara. J Therm Biol 3:39-41

Rosen PC (1991) Comparative field study of thermal preferenda in garter snakes (Thamnophis). J Herpetol 25:301-312

Scott JR, Pettus D (1979) Effects of seasonal acclimation on the preferred body temperature of Thamnophis elegans vagrans. J Therm Biol 4:307-309

Secor SM (2001) Regulation of digestive performance: a proposed adaptive response. Compar Biochem Physiol A 128:565-577 
Secor SM (2009) Specific dynamic action: a review of the postprandial metabolic response. J Compar Physiol B 179:1-56

Secor SM, Boehm M (2006) Specific dynamic action of ambystomatid salamanders and the effects of meal size, meal type, and body temperature. Physiol Biochem Zool 79:720-735

Secor SM, Diamond J (1997) Determinants of the postfeeding metabolic response of Burmese pythons, Python molurus. Physiol Zool 70:202-212

Secor SM, Phillips JA (1997) Specific dynamic action of a large carnivorous lizard, Varanus albigularis. Compar Biochem Physiol 117A:515-522

Secor SM, Wooten JA, Cox CL (2007) Effects of meal size, meal type, and body temperature on the specific dynamic action of anurans. J Compar Physiol B 177:165-182

Shine R, Lambeck R (1990) Seasonal shifts in the thermoregulatory behavior of Australian blacksnakes, Pseudechis porphyriacus (Serpentes: Elapidae). J Therm Biol 15:301-305

Sievert LM, Andreadis P (1999) Specific dynamic action and postprandial thermophily in juvenile northern water snakes, Nerodia sipedon. J Therm Biol 24:51-55

Sievert LM, Hutchison VH (1989) Influences of season, time of day, light and sex on the thermoregulatory behavior of Crotaphytus collaris. J Therm Biol 14:159-165

Sievert LM, Jones DM, Puckett MW (2005) Postprandial thermophily, transit rate, and digestive efficiency of juvenile cornsnakes, Pantherophis guttatus. J Therm Biol 30:354-359

Temple JG (2002) Using magnetic stir bars to determine digestive passage rate in an ectotherm, the garter snake. Am Biol Teach 64:52-57

Toledo LF, Abe AS, Andrade DV (2003) Temperature and meal size effects on the postprandial metabolism and energetics in a boid snake. Physiol Biochem Zool 76:240-246

Touzeau T, Sievert LM (1993) Postprandial thermophily in rough green snakes. Copeia 1993:1174-1176

Tsai T-S, Tu M-C (2005) Postprandial thermophily of Chinese green tree vipers, Trimeresurus s. stejnegeri: interfering factors on snake temperature selection in a thigmothermal gradient. J Therm Biol 30:423-430

Tu M-C, Hutchison VH (1995) Interaction of photoperiod, temperature, season, and diel cycles on the thermoregulation of water snakes (Nerodia rhombifera). Copeia 1995:289-293

Wang T, Busk M, Overgaard J (2001) The respiratory consequences of feeding in amphibians and reptiles. Compar Biochem Physiol 128A:535-549

Withers PC (1992) Comparative animal physiology. Saunders College Publishing, Fort Worth

doi:10.1186/1810-522X-52-33

Cite this article as: Sievert et al.: Specific dynamic action, postprandial thermophily, and the impact of temperature on gastric digestion in the cornsnake Pantherophis guttatus. Zoological Studies 2013 52:33.

\section{Submit your manuscript to a SpringerOpen ${ }^{\circ}$ journal and benefit from:}

- Convenient online submission

- Rigorous peer review

- Immediate publication on acceptance

- Open access: articles freely available online

- High visibility within the field

- Retaining the copyright to your article

Submit your next manuscript at $\gg$ springeropen.com 